\title{
La actio de in rem verso en la jurisdicción contenciosa administrativa colombiana
}

\section{The act of in rem verso in the Colombian administrative contentious jurisdiction}

Tania Sofia Palma Árias ${ }^{1}$

RECIBIDO: $15-03-18$

ACEPTADO: 15-09-18

\section{Resumen}

Este artículo hace un análisis sobre la acción de reembolso y su desarrollo en la jurisdicción contenciosa administrativa, así como de su relación con los medios de control estipulados en la Ley 1437 de 2011, y determinar si el enriquecimiento sin razón válida, se erige como un título jurídico de imputación. En este sentido, se hará en primer lugar un estudio teórico sobre el enriquecimiento injustificado, sus orígenes, generalidades, características y procedencia; posteriormente se tratará el tema desde la óptica de la jurisdicción contenciosa administrativa, para lo cual se presentará la línea jurisprudencial actualizada del Consejo de Estado, para culminar en el tema del medio de control adecuado para alegarlo, y si este se constituye como un título de imputación. Finalmente se estudiará el problema jurídico desde el derecho comparado, para lo cual se mirará las doctrinas y jurisprudencias chilena y ecuatoriana.

Palabras clave: acción de in rem verso, contencioso administrativo, derecho comparado, daño patrimonial, provecho económico.

\section{Abstract}

This article analyzes the reimbursement action and its development in the contentious administrative jurisdiction, as well as its relationship with the means of control stipulated in Law 1437 of 2011, and determine if the enrichment without valid reason, stands as a legal title of imputation. In this sense, a theoretical study on the unjustified enrichment, its origins, generalities, characteristics and origin will be made in the first place; subsequently the subject will be treated from the point of view of the contentious administrative jurisdiction, for which the updated jurisprudential line of the Council of State will be presented, to culminate in the topic of the means of adequate control to claim it, and if this is constituted as a title of imputation Finally, the legal problem will be studied from comparative law, for which Chilean and Ecuadorian doctrines and jurisprudences will be examined.

Kerwords: action in rem verso, contentions administrative, comparative law, property damage, economic profit.

1 Abogada litigante y magíster en derecho. Abogada. taniapalmaarias@gmail.com 


\section{INTRODUCCIÓN}

El enriquecimiento injustificado y la acción de in rem verso son de vieja data en el sistema jurídico de nuestro país. La Corte Suprema de Justicia en su Sala de Casación Civil sentó jurisprudencia en providencia fechada en noviembre 19 de 1936, indicando que se requiere el enriquecimiento del obligado por ventaja patrimonial, un empobrecimiento correlativo de una persona y que el accionante no cuente con otro mecanismo judicial a su alcance. Ciertas condiciones romanas, junto con la actio in rem verso eran mecanismos para reparar actos injustos originados de acciones legales. Para la Corte Suprema de Justicia la acción de in rem verso es autónoma y procede para corregir el enriquecimiento injustificado. En igual sentido se pronuncia el Consejo de Estado, que en el transcurso del siglo XX reconoce a la figura estudiada, como fuente de obligaciones y varía su postura frente al medio procesal para encausarla; en sentencia unificada dictada en noviembre 19 de 2012, expone que la actio de in rem verso, no sirve para demandar la ejecución de obras o pagos de emolumentos o servicios prestados sin el cumplimento de las formalidades legales, como la suscripción de un contrato estatal. La acción de reembolso tiene un fundamento moral, y busca que nadie se enriquezca a costa de otra persona.

En sentencia de marzo 10 de 2017, el Consejo de Estado reitera que la acción estudiada procede excepcionalmente y por interés público o general, cuando la administración ejerce presión o constreñimiento sobre la persona empobrecida, para inducirla a prestar un servicio obviando las formalidades de la contratación; también, cuando estas actividades se realizan con la finalidad de preservar la prestación de servicios de salud, y ante la existencia de urgencia manifiesta no siendo posible observar el proceso de contratación estatal. La actio de in rem verso es subsidiaria, excepcional, única y de rango compensatorio.

El enriquecimiento sin causa de la administración estatal se tramita como un título jurídico de imputación del daño, de acuerdo con el régimen de responsabilidad consagrado en la Constitución Política, en su artículo 90.

El derecho ecuatoriano configura la acción in rem verso, similar al caso colombiano porque exige la disminución injustificada de un patrimonio, el enriquecimiento de un ente estatal y un nexo entre ambos; asi mismo, busca compensar el daño patrimonial producido y se soporta en el principio de 
equidad que gobierna toda actuación o procedimiento judicial. En el derecho chileno se reprocha el incremento sin justa causa del patrimonio de un sujeto en detrimento del patrimonio de otro, y el legislador construyó la acción de in rem verso para obligar al injustamente beneficiado que reembolse lo apropiado.

Bajo este contexto, se presenta un artículo en el cual se recopilan sendas decisiones del Consejo de Estado colombiano, matizado con doctrina nacional y extranjera en donde se depura el tema del enriquecimiento sin causa, no solo como principio general y fuente de las obligaciones, sino también como título de imputación.

\section{GENERALIDADES DEL ENRIQUECIMIENTO SIN CAUSA Y DE LA ACTIO IN REM VERSO}

Con el fin de introducirse de fondo en el tema en cuestión, es necesario primero hacer ciertas consideraciones acerca del origen de la figura estudiada, en el marco jurídico colombiano. En tal sentido, una de las primeras y más importantes decisiones jurisprudenciales acerca del enriquecimiento sin causa, la profirió la Corte Suprema de Justicia en su Sala de Casación Civil, en noviembre 19 de 1936, en la cual delineó sus requisitos y ámbito de aplicación (Cabra Camargo, 2014, p. 33). Quiere decir lo anterior, que es esta decisión del máximo órgano de la jurisdicción ordinaria, fechada a principios del siglo $X X$, donde se decantan los primeros esbozos de este instituto jurídico en la normatividad colombiana, y donde se refieren a ella como fuente de obligaciones y principio general del derecho (Corte Suprema de Justicia. Sala de Casación Civil. Sentencia 6.j.1918, 1936, p.474).

De esta forma, aunque en esa época no existía una normatividad taxativa que regulara el enriquecimiento injusto, jurisprudencialmente han aplicado dicho principio, con base en los artículos 4, 5, 8 y 48 de la Ley 153 de 1887, que establece las formas de interpretación de la ley y sus fuentes auxiliares.

Valencia Zea y Ortiz Monsalve señalan que para que prospere una pretensión por enriquecimiento sin justa causa, deben concurrir los siguientes elementos: que exista un aumento de patrimonio a cargo de una parte favorecida, y coetáneamente una disminución de capital de la parte afectada, asi mismo que ese traslado patrimonial carezca de una causa jurídica. Por lo demás el actor no debe contar con otra vía procesal para obtener la debida compensación, y la 
acción in rem verso no puede contrariar la ley (Valencia Zea \& Ortiz Monsalve, 1998, p.310).

Como se ha podido observar, los elementos de esta fuente de obligaciones implican, por una parte, que se produzca un incremento patrimonial y que el sujeto llamado a responder se beneficie de esto; de aquí se deduce que hay otro sujeto que resulta perjudicado con el detrimento en su capital y por tanto es víctima de empobrecimiento, y que la relación entre ambos sujetos es que uno de ellos obtiene un provecho económico perjudicando al otro, cuyo patrimonio resulta deteriorado o disminuido. Por otra parte, quien demanda no debe disponer de otro tipo de acción judicial para estos fines, y la acción resulta impróspera cuando con su ejercicio se pretende desconocer un precepto legal obligatorio; siendo la finalidad del enriquecimiento injusto, compensar el desequilibrio patrimonial causado, pero no obtener un resarcimiento o indemnización.

Por su lado, Baena Gómez ubica esta figura dentro del derecho administrativo como aquella utilizada para no admitir el enriquecimiento a los ojos de la moral pública, planteando un deber de este tipo y regulando los postulados que rigen al derecho patrimonial (Baena Gómez, 2014, p.13).

Se puede inferir entonces que para Baena Gómez, la actio in rem verso tiene un fuerte soporte moral, pues considera inexcusable el enriquecimiento, el que implica o apareja consecuencialmente la obligación moral de resarcimiento 0 restitución, como fuente básica y norma rectora del derecho patrimonial, la cual tiene como pauta que dentro de las relaciones comerciales han de funcionar los fundamentos de la justicia conmutativa, siendo sostenida en un motivo validado jurídicamente en el marco legal, y que conduce necesariamente al deber de reembolsar el monto de aquello que fue motivo de enriquecimiento indebido. Lo anterior implica que la acción estudiada pretende compensar el perjuicio sufrido por el sujeto afectado con el desequilibrio económico, tanto moral como patrimonialmente.

Por otro lado, no debe confundirse el enriquecimiento sin causa con el enriquecimiento ilícito tipificado en los artículos 327 y 412 de nuestro código Penal, que castiga al particular o servidor público que aumente de forma injustificada su patrimonio. Sobre el particular, Valencia Zea y Ortiz Monsalve indican que el derecho sancionatorio penaliza la conducta dolosa de incre- 
mentar el patrimonio, como consecuencia de realizar acciones fraudulentas 0 violatorias de la ley, mientras que el enriquecimiento ilegitimo se produce por una descompensación patrimonial entre dos partes, que se origina sin causa legal (Valencia Zea y Ortiz Monsalve, 2011, p.227).

De esta forma, el enriquecimiento injusto es fuente de obligaciones en materia civil, comercial y administrativa, y el enriquecimiento ilícito es una conducta penal sancionada conforme a la normatividad vigente.

Los origenes del principio estudiado se remontan al Digesto de Justiniano que es la primera codificación del derecho romano, que hace alusión al tema en el campo del derecho natural, y que señala que "por derecho natural es equitativo que nadie se haga más rico con detrimento e injuria de otro" (Micolta Gil, 2014, p.147).

En consecuencia, esencialmente la acción busca que nadie se enriquezca a costa de otra persona, procura como acción autónoma la recuperación de la suma motivo de enriquecimiento y es la finalidad de esta, reparar el daño que por ello se ha producido.

Para Micolta Gil, la actio in rem verso es personal, general, autónoma y subsidiaria, y se acoge a la postura reciente de la jurisdicción contenciosa donde es calificada como una pretensión de índole compensatoria (Micolta Gil, 2014, pp.26, 27).

Se colige de lo anterior que este tipo de acción judicial se emplea siempre que ocurra un acrecentamiento de tipo patrimonial de un sujeto frente a otro, sin causa legal que lo permita; en segundo lugar porque el sujeto objeto de detrimento patrimonial carece de otro medio para validar sus intereses, de modo que tal institución jurídica es de tipo sucedáneo, y a voces del Consejo de Estado es una aspiración donde se pretende restituir a quien ha sido víctima de un enriquecimiento sin causa.

Ahora bien, en los anales del derecho romano existieron varias condiciones que se empleaban como soluciones aplicables a remediar actos injustos producidos por actuaciones válidas. Para Arias Fonseca, las denominadas condictiones romanas eran mecanismos para reparar actos injustos originados de acciones legales, entre ellas la condictio ob causam datorum o condictio causa data causa non secuta, la cual se empleaba cuando había detrimento 
patrimonial por cuenta de una promesa o condición futura y lícita, o cláusula aplicable dentro de un determinado contrato, la cual no se llegaba a cumplir, y por ende quien esperaba su beneficio terminaba finalmente perjudicado, o porque pactada una determinada obligación de un contrato real, esta no se cumplía a cabalidad, lo que implica entonces el ejercicio de una cláusula suspensiva en el tiempo (Arias Fonseca, 2013, p.152).

Otro tipo de acciones son la condictio indebiti, utilizada por el perjudicado que de forma errónea cancelaba una obligación no debida, la condictio ob turpem causam, otorgada a los afectados con una promesa inmoral y la condictio ob iniustam causam conferida al perjudicado con una prestación contraria a derecho (Arias Fonseca, 2013, p.152).

En síntesis, la condictio indebiti se concedía a quien pagaba erróneamente una deuda que no existía; la condictio ob turpem causam, empleada cuando se había consentido o pactado una obligación originada en un hecho amoral; la condictio ob iniustam causam, aplicable cuando el compromiso hecho no era ajeno a la moral, pero sí iba contra la normatividad jurídica. Finalmente, y para el caso de la mayoría de las circunstancias de detrimento patrimonial, se configuraba la condictio sine causa; donde no existiera la equidad, se empleaba la actio de peculio o in rem verso, materia de estudio de esta investigación, que inicialmente se había diseñado para aquellos asuntos en donde se contrataba con un alieni iuris que no autorizaba el paterfamilias, o padre de familia, pero que con el transcurrir del tiempo, se transformó en la acción por excelencia para aplacar los efectos nocivos de las situaciones donde existía un claro enriquecimiento sin causa.

Recordemos que el paterfamilias, de acuerdo con el derecho romano, es cualquier hombre que no dependía de otro, y ejercía autoridad sobre la familia y la propiedad (De Coulanges, 2003, p.81). Por lo tanto, siendo el paterfamilias el representante de la familia, era el único con la potestad de ejercitar la actio de peculio.

Ahora bien, pese a que la existencia de la acción en comento se remonta al derecho romano, también la reconoce la escuela exegética francesa, que la admitió como una acción complementaria a la de gestión de negocios ajenos.

Escribió el profesor Barrientos que los principales juristas que continuaron la doctrina defendida por Pothier y por los primeros comen- 
taristas del Code Civil que admitieron la existencia de una acción especial de in rem verso vinculada a la gestión de negocios, fueron Jean-Baptiste Henri Duvergier (1792-1877), Frederic Mourlon (18111866), Léobon-Valéry-Léon-Jupile Larimbiére (1813-1893), Charles Demolombe (1804-1888), Francois Laurent (1810-1887), Théophile Huc (1829-1906), y algunos otros como Gabriel Massé (1807-1881) y Charles-Henri Vergé (1810-1890). (Bohórquez Yepes, 2014, p.39)

Dicho de este modo, varios adeptos en materia jurídica de la escuela exegética francesa de mediados del siglo XIX reconocen la acción de reembolso como adicional en el marco de la gestión comercial, y aplicable en asuntos tales como aquellos donde no era posible concretar una misión de negocios ajenos (Barrientos Grandón, 2000).

En esencia, la acción de in rem verso tenía como aspiración: "obtener la repetición de todo aquello en lo que se hubiera enriquecido la persona en cuyo favor se había realizado el negocio, precisamente porque el instrumento se enfocaba hasta el momento del enriquecimiento" (Bohórquez Yepes, 2014, p.39). Luego entonces, a pesar del origen romano de la figura estudiada, es claro el aporte de la escuela exegética francesa que reforzó el matiz moderno de acción compensatoria.

\section{LA ACCIÓN DE IN REM VERSO EN LA JURISDICCIÓN CONTENCIOSA ADMINISTRATIVA. LINNEA JURISPRUDENCIAL}

La sentencia más antigua relacionada en el sistema de relatoría del Consejo de Estado es del año 1968, y en ella se siguen las huellas de la doctrina francesa, expuesta especialmente por Ripert, Planiol, Aubry y Rau, exponiendo que la jurisprudencia colombiana ha fijado cinco condiciones de la acción in rem verso, reseñando las siguientes:

10. Que el obligado haya obtenido una ventaja patrimonial. 2o Que haya un empobrecimiento correlativo, lo cual significa que la ventaja obtenida por el enriquecido haya costado algo al empobrecido. 30 Que el enriquecimiento carezca de causa, es decir, que la circunstancia que produjo el desplazamiento de un patrimonio a otro no haya sido generada por un contrato o un cuasicontrato, un delito 0 un cuasidelito como tampoco por una disposición expresa de la ley. 40 Que el demandante carezca de cualquiera otra acción. 5o La 
indemnización no puede sobrepasar el límite del desplazamiento patrimonial. (Sentencia, 1968)

Otra sentencia importante es el fallo de Consejo de Estado, fechado en noviembre 30 de 2000, en la cual se argumenta que en casos donde el daño se origina de la prestación de un servicio o suministro de bienes, sin mediar contrato solemne y atemperado a la normatividad legal pertinente, es posible aspirar a que se declare la existencia del negocio jurídico, por medio del ejercicio de la acción contractual, y dicha acción es procedente o alternativamente la de reparación directa, siempre y cuando se pueda determinar que los sujetos procesales han actuado de tal forma que se configuran los elementos del tipo de negocio que se plantea, es decir, si su conducta comercial o legal se adecúa dentro de las formalidades del contrato que aspiraban concretar (Consejo de Estado, Sala de lo Contencioso Administrativo, Sección Tercera, Sentencia, Radicación; 11895, 2000).

Corolario a lo expuesto, si se demuestra que concurrieron los elementos y requisitos del contrato, tal como la exige la normatividad vigente en la materia, es procedente la declaratoria de existencia y eficacia del negocio, y declara que el mismo ha existido, teniendo como medio de defensa idóneo la acción contractual; en caso que tales condiciones no se reúnan, no resulta próspera la acción contractual, por cuanto hay una notable ausencia de todas las pruebas, trámites y elementos necesarios que permitan solemnizar por escrito dicho contrato y que lleven a su posterior perfeccionamiento, por tanto es claro señalar que el negocio jurídico no existe.

La tercera sentencia objeto de análisis la profirió el Consejo de Estado, en mayo 12 de 2011, dentro del radicado 26758, donde indica que si la litis trabada se origina en un contrato estatal, la acción que procede es la de controversias contractuales, descrita actualmente como medio de control en el artículo 141 de la Ley 1437 de 2011, con la finalidad de declarar, sea la nulidad del contrato 0 de los actos administrativos contractuales, por resultar violentada la normatividad jurídica en la materia. Aclara el alto tribunal que la acción in rem verso, siendo autónoma e independiente, no prospera para el tema de los contratos que suscribe el Estado, por cuanto para estos casos existe la acción de controversias contractuales, y porque el enriquecimiento originado en estas condiciones tiene una causa legitima derivada de un acuerdo de voluntades con la administración (Patiño, 2010, p.402). 
En síntesis, si la discusión jurídica emerge de un contrato estatal, resulta altamente inconveniente la actio in rem verso que es de especial aplicabilidad, porque de un lado el traslado patrimonial cuya corrección se pretendería, tendría como causa un contrato con la administración, lo que desvirtuaría un presunto enriquecimiento ilegítimo, y por el otro, la acción de reembolso es autónoma, independiente y subsidiaria y no es operante junto a la acción de controversias contractuales.

Sin embargo, anteriormente el Consejo de Estado había decantado ampliamente la figura del enriquecimiento sin causa frente a la actio de in rem verso, en sentencia fechada en marzo 30 de 2006, expediente 25662, donde expuso que dicho instituto jurídico responde a un principio generalmente reconocido que prohíbe el enriquecimiento ilegítimo de una parte, en contra de otra, la cual resulta con detrimento patrimonial, y que, ciertamente la actio de in rem verso se concibe como el mecanismo procesal para evitar tal enriquecimiento. En el derecho romano, como se explicó anteriormente, existían múltiples condictiones, que se utilizaban para corregir los acrecentamientos patrimoniales derivados de actos válidos pero con fundamento injusto y con la misma finalidad de la acción de in rem verso, que se asimila a ella por la equidad que aplica para corregir el enriquecimiento injustificado.

Presentemente la sentencia más importante es la proferida por la Sala Plena de la Sección Tercera del Consejo de Estado en noviembre 19 de 2012, que en síntesis, para referirse a la acción estudiada señala como regla general, que esta no puede ser utilizada para demandar la ejecución de obras o pagos de emolumentos o servicios prestados sin el cumplimento de las formalidades legales, como la suscripción de un contrato estatal, toda vez que en las relaciones contractuales que la administran impera la buena fe objetiva, que supone el cumplimiento de lo pactado con sometimiento de la ley, o sea, respetando las formalidades y solemnidades del contrato; sin embargo en esta sentencia de unificación, se consideran tres excepciones a esta regla, y es que se puede invocar el enriquecimiento sin causa con ausencia de contrato, cuando la administración ejerce coacción sobre el particular para obtener la prestación del servicio o suministro de bienes; cuando es necesario preservar la prestación de los servicios de salud, y en los casos de urgencia manifiesta debidamente acreditada, cuando se omite dicha declaratoria y se impone una carga al empobrecido. Así mismo, en esta providencia se deja claro que la demanda es meramente compensatoria con límite en el monto del empobre- 
cimiento; y que la vía adecuada para invocarla es la reparación directa, debido a que la actio de in rem verso tiene una autonomía sustancial mas no procedimental, razón por la cual debe tomarse como una pretensión que busca el equilibrio patrimonial afectado por la administración estatal (Consejo de Estado, Sala de lo Contensioso Administrativo, Sección Tercera, Sentencia Radicado: 73001-23-31-000-2000-03075-01 (24897)).

Luego entonces, según esta posición doctrinal del Consejo de Estado, la regla general es que el enriquecimiento incausado, y colateralmente la actio de in rem verso, son principios generales en el derecho colombiano, pero que su autonomía es meramente sustancial, porque para su ejecución es necesaria invocarla como una pretensión dentro del medio de control de reparación directa.

Esta posición no fue pacífica en el máximo tribunal de la jurisdicción contenciosa administrativa, pues la magistrada Stella Conto Díaz Del Castillo profirió un elogiado Salvamento de Voto, en el cual argumenta sus razones para apartarse de la decisión mayoritaria. En dicho manifiesto expresa, que ante las decisiones contradictorias surgidas en la Sala durante varias décadas era necesario sentar una posición unificada sobre el tema, empero, no está de acuerdo con la decisión adoptada por la mayoría, que le restó importancia y trascendencia a la actio de in rem verso como la vía procesal para conjurar los desplazamientos patrimoniales originados en la actuación del Estado; expone que no se puede confundir la acción de origen romano con la reparación directa, debido a que ambas tienen características esenciales que las hacen diferentes y autónomas. Indica que la acción contenciosa administrativa está dirigida a obtener la declaración de responsabilidad extracontractual de la administración, con la respectiva indemnización del daño antijurídico; mientras que los casos de enriquecimiento injustificado, no suponen la existencia de un daño que el particular no esté en el deber de soportar, sino un desplazamiento patrimonial que debe ser corregido mediante la compensación. La doctora Díaz Del Castillo hace énfasis en la aplicación del principio de buena fe, el cual se presume en todas las relaciones, contrario a lo indicado en la decisión debatida, donde se insinuó que la buena fe objetiva no es presumida, así mismo señala que las excepciones expuestas en la sentencia no están acordes con la jurisprudencia de la Corporación, pues son típicos casos de falla en el servicio; y finaliza señalando que con la decisión de unifi- 
cación, el enriquecimiento sin causa quedó como una figura ilusoria en esta jurisdicción (Salvamento de Voto, 2012).

Como puede observarse en el Salvamento de Voto se critica la posición mayoritaria que restó autonomía a la acción de reembolso enmarcándola dentro del medio de control de reparación directa, pues ambas acciones son diferentes en procedencia y finalidad, además que con este cambio jurisprudencial se deja inoperante una figura de vieja data en nuestro país.

Otra decisión importante por estudiarse, es el fallo dictado dentro del radicado 05001-23-31-000-2012-00690-01 (54121) de marzo 10 de 2017, emanado del máximo órgano de la jurisdicción contenciosa, donde se reafirma la postura mayoritaria sobre el tema, explicando con mayor claridad las excepciones en las que procede la acción estudiada.

Como punto de partida, la Sala remarca que en los casos en los cuales la administración ejerce fuerza o coacción sobre el afectado, y sin que medie contrato estatal con las formalidades legales, lo constriñe a realizar operaciones, a prestar sus servicios o a suministrar bienes, haciendo uso de su poder o fuerza dominante, y sin que medie la culpa del particular, es procedente que se ejerza la actio de in rem verso, eso sí, utilizando la vía procesal de la reparación directa, a fin de que el empobrecido recupere lo perdido, sin derecho a recibir indemnización (Consejo de Estado, Sala de lo Contencioso Administrativo, Sección Tercera, Sentencia 05001-23-31-000-2012-00690-01 (54121), 2017).

De lo expuesto se infiere que el primer caso se trata de aquellas situaciones en las cuales se prueba contundentemente en el proceso que la entidad pública, justamente y $\sin$ que medie responsabilidad de la parte empobrecida, ostentando su autoridad o posición dominante, mediando constreñimiento, le cargó injustificadamente al particular la ejecución de prestaciones u otras obligaciones, sin mediar contrato escrito, caso en el cual la responsabilidad estatal está crasamente comprometida, porque vulnera el ordenamiento jurídico.

El alto tribunal de lo contencioso administrativo tuvo en cuenta esta excepción al resolver la litis dentro del radicado 19045 , donde una empresa de seguridad privada que prestaba sus servicios al municipio de Arauca, cumplió con sus obligaciones contractuales hasta el mes de diciembre de 1997, sin embargo, la administración municipal la sedujo a seguir prestando el servicio, ante 
la falta de presupuesto y porque la protección de las instalaciones de la Alcaldía no podía suspenderse, razón por la cual la empresa continuó con su labor hasta el mes de mayo de 1999, sin que el ente territorial le pagara por sus servicios; en este caso, la Sala consideró que si el ente público había provocado con su conducta que la empresa particular siguiera prestando el servicio de vigilancia sin previamente haberse surtido el proceso contractual, generó de esta forma un desplazamiento patrimonial injusto, el cual se debía corregir pagando la compensación respectiva (Consejo de Estado, Sala de lo Contencioso Administrativo, Sección Tercera, Sentencia 19045, 2013).

La segunda excepción que decanta el Consejo de Estado en el radicado 54121, se relaciona con el derecho a la salud, y la importancia de que la prestación de dicho servicio no se interrumpa; en esta providencia indica que una parte puede solicitar el reconocimiento de un enriquecimiento injusto a cargo de un ente público, cuando le ha proveído bienes o servicios, en casos de urgencia, donde no es posible adelantar de forma adecuada el proceso contractual, para no comprometer la continuidad en la prestación del servicio de salud (Consejo de Estado, Sala de lo Contencioso Administrativo, Sección Tercera, Sentencia 05001-23-31-000-2012-00690-01 (54121), 2017).

Analizada esta situación, se tiene que cuando de carácter urgente se deben adquirir bienes o servicios, suministros, o realizar obras para garantizar que se siga prestado de manera adecuada el servicio público de salud, y precaver una lesión indefectible a este derecho de carácter fundamental, la urgencia de tales contratos o actos administrativos es manifiesta y evidente, porque hay imposibilidad total para su planificación y el agotamiento del proceso para escoger contratistas, para formalizar contratos, todo lo cual ha de demostrarse en la respectiva actuación contencioso administrativa, siendo procedente una acción de reembolso para que el particular afectado recupere su inversión.

La última excepción de que se ocupa la jurisprudencia es de aquellas situaciones que se generan cuando la entidad pública, siendo procedente la declaratoria de urgencia manifiesta, omite esta formalidad y procede a deprecar a un particular la prestación de algún servicio, o ejecución de obras, sin la solemnidad de un contrato (Consejo de Estado, Sala de lo Contencioso Administrativo, Sección Tercera, Sentencia 05001-23-31-000-2012-00690-01 (54121), 2017). 
Con base en lo expuesto, debe explicarse que cuando se suscitan situaciones en las que una entidad estatal requiere de un particular para la ejecución de una prestación con carácter urgente, dado que se ha presentado alguna de las causales de urgencia manifiesta, aunque no proceda a su declaratoria, debe responder por las erogaciones causadas por esa persona, pues de lo contrario se enriquecería injustamente con cargo al patrimonio del afectado.

\section{DEFINICIÓN Y ELEMENTOS}

Pese a que en páginas anteriores se ha expuesto en qué consiste la acción estudiada, es prudente traer a colación los conceptos precisos de algunos tratadistas en la materia. Para Armenta Ariza, la actio de in rem verso es el medio judicial para obtener el reconocimiento del principio del enriquecimiento sin causa, indicando que este es aplicable por el juez de lo contencioso, de la misma forma en que lo hace la jurisdicción ordinaria al remitirse a la Ley 157 de 1887 en su artículo 8 (Armenta Ariza, 2009, p.96).

Con base en lo expuesto, este tipo de acción procede cuando el juez administrativo aplica el principio de que nadie puede enriquecerse injustamente a costa de otro. Se indica que en temas contenciosos administrativos no está consagrada expresamente y que nuestra Corte de Casación la emplea con fundamento en la Ley 153 de 1887, para llenar el vacío legal que permite las reglas generales del Derecho.

Ahora bien, el mismo autor señala que para el Consejo de Estado la acción de reembolso es una pretensión dentro del medio de control de reparación directa, mecanismo por excelencia dentro de la jurisdicción administrativa para reparar faltas estatales, pero que analizada la naturaleza del principio estudiado, la acción contenciosa no sería procedente en cuanto riñe con la subsidiaridad que la identifica (Armenta Ariza, 2009, p. 97).

Por su lado, Cabra Camargo se preocupa por establecer diferencias entre el enriquecimiento sin causa frente a la actio in rem verso, y explica que su contraste estriba en que la primera es una regla general, que no permite el aumento incausado de un patrimonio a costa del empobrecimiento de otro, y la segunda es el mecanismo jurídico para encausar la pretensión que se origina del principio citado (Cabra Camargo, 2014, p.51). 
En este orden de ideas, evidentemente el enriquecimiento injustificado y la acción de reembolso son dos creaciones jurídicas totalmente diferentes, y que esencialmente su disimilitud comprende que uno es principio general de derecho, que no permite el incremento patrimonial injustificado, y el otro una figura procesal, instituto jurídico o acción judicial mediante la cual se invoca la pretensión para reclamar los derechos cuando resulta vulnerada dicha regla universal.

La misma publicación puntualiza las características de la acción estudiada, indicando como la primera de ellas, que este mecanismo judicial es de tipo subsidiario o supletorio, es decir que procede exclusivamente cuando el perjudicado carezca de otro tipo de medio jurídico o administrativo, para obtener el resarcimiento patrimonial esperado.

La segunda característica se refiere a su excepcionalidad, porque la transferencia o incremento patrimonial injustificado que conduce al enriquecimiento alegado o enriquecimiento sin causa, de ninguna manera puede originarse en las fuentes legales y formales de las obligaciones consagradas en el artículo 1494 de nuestro estatuto sustancial civil.

Y la última peculiaridad de esta acción se relaciona con su naturaleza compensatoria, pues la acción in rem verso tiene como fin último o como objetivo solamente la actividad compensatoria al afectado con el enriquecimiento sin causa, porque mediante su ejercicio no es posible conseguir indemnización o resarcimiento de un perjuicio, su alcance solamente es respecto del monto al cual resultó defraudado el afectado y se incrementó el patrimonio del demandado, y que necesariamente comprende la disminución patrimonial sufrida por el demandante, diferente de la reparación directa que se constituye como una acción meramente indemnizatoria. (Cabra Camargo, 2014, p.51)

Ahora bien, quedó claro que el enriquecimiento incausado es una regla universal del derecho y la acción de reembolso es el mecanismo judicial para evitarlo. Es decir, que uno es consecuencia del otro.

Para Herrera Montañez, la prohibición de obtener incremento patrimonial en perjuicio de otro, sin una causa legal que así lo permita, ha sido llamado por la doctrina enriquecimiento injusto, y exige como requisitos esenciales, que 
en primera medida exista un aumento en el patrimonio de una de las partes; en segundo lugar, un correlativo empobrecimiento de otro sujeto; en tercer lugar, que la mutación del patrimonio no tenga causa justificada, y finalmente, que el perjudicado con la disminución patrimonial no tenga otro medio de defensa judicial que le permita obtener por su conducta el resarcimiento al daño padecido (Herrera Montañez, 2016, p.23).

El mismo tratadista indica que la jurisprudencia de la Corte Suprema ha sido tajante en señalar la improcedencia de la acción in reverso, sino subsidiariamente de otra y siempre que se configure el enriquecimiento sin causa con todos sus requisitos.

En síntesis, dicho mecanismo judicial se aplica subsidiaria y alternativamente con otro casi de la misma naturaleza, cuando el demandado haya obtenido incremento patrimonial, y el demandante sufra en el mismo monto, un desmedro o perjuicio en su patrimonio y que ese movimiento de bienes no tenga causa justificada dentro del orden normativo vigente.

\section{EL ENRIQUECIMIENTO SIN CAUSA, ¿TíTULO JURÍDICO DE IMPUTACIÓN DE RESPONSABILIDAD DE LA ADMINISTRACIÓN?}

Para tener claro si el enriquecimiento injustificado puede funcionar como título jurídico de imputación de responsabilidad estatal, es necesario precisar que mediante esta figura es posible solucionar la problemática que se presenta cuando se concretiza un desequilibrio económico sin justificación entre dos sujetos, el cual carece de respaldo en la normatividad jurídica. Esta figura como tal tiene sus ancestros en el derecho romano, como respuesta a impedir que una persona incremente su patrimonio en desmedro de otra, lo cual no es jurídica ni moralmente aceptado (Meléndez Julio, 2015, p.384).

Las afirmaciones anteriores implican colegir que ciertamente la actio in rem verso representa la acción por medio de la cual se pretende el resarcimiento por incremento patrimonial injustificado. Ya se ha dicho que en el derecho romano fueron un abanico de posibilidades enderezadas a recuperar el equilibrio patrimonial quebrantado sin justificación, pero tales figuras no calaron tan hondo en la cultura jurídica colombiana como lo hizo la acción de rembolso, pero tienen en común que con ellas se busca restablecer la equidad, la justicia y el equilibrio que sirven de base para el enriquecimiento sin causa. 
En otra línea argumentativa, el Estado no está autorizado para enriquecerse perjudicando a los particulares, que como sujetos destinatarios de cobros de tasas y todo tipo de impuestos tributarios ayudan con sus ingresos a su sostenimiento.

Debe recordarse que, bajo la égida de la Constitución Política colombiana, especialmente en su artículo 90, las organizaciones estatales, entre las que se incluyen las entidades territoriales, responden con su patrimonio o en general con su presupuesto, por los daños antijurídicos que se le imputen, originados por acción u omisión de sus representantes o agentes, y de allí deviene la estipulación general de responsabilidad estatal, para dar cobertura a todas las situaciones que sobre el particular se configuren.

Como bien lo explica García de Enterría (2006), las causas de imputación son "aquellas circunstancias en virtud de las cuales es posible establecer una relación entre el daño y el sujeto imputado que justifique atribuir a éste el deber de reparación que la antijuridicidad del daño impone". (p.203). El enriquecimiento injusto es una forma de imputación de responsabilidad estatal, la cual no se justifica en los vínculos entre la actividad de la administración y el daño causado, sino en el beneficio recibido por una de las partes (la administración) y que genera un empobrecimiento coetáneo al particular (Navia Arroyo, 2000).

En tal sentido, la doctrina nacional es clara en indicar respecto a la imputación por enriquecimiento sin causa, que bajo la cláusula general de responsabilidad consagrada en el artículo 90 de la Carta Política, se pueden incluir todos los eventos en que la actividad de la administración conlleve al resarcimiento de un perjuicio, y así lo hacía la jurisprudencia contenciosa administrativa que tenía en cuenta la tesis del profesor García de Enterría al resolver los casos de ventaja patrimonial injustificada (Useche Perdomo, 2014, p.11).

Así las cosas, siendo evidente el concepto jurídico de la responsabilidad estatal para incluir dentro de la misma todas las situaciones en las cuales los agentes estatales, sea por acción u omisión, acarrean un daño antijurídico a particulares, anteriormente la jurisprudencia en materia administrativa defendía la tesis del autor español García de Enterría, que planteaba la imputación por enriquecimiento injusto, como título para atribuir responsabilidad estatal.

Por su lado Bohórquez Yepes, indica: 
El enriquecimiento sin causa es principio universal, la responsabilidad del Estado por daño antijurídico es una expresión constitucional, de donde surge que se entrelazan para cumplir los cometidos de un orden social justo y responder a uno de los postulados esenciales del ordenamiento jurídico de una nación civilizada: tener expresión constitucional, pero sin dejar de lado que la conducta de la víctima se integra al núcleo de ese sistema. Al considerarse en el fallo de unificación de 19 de noviembre de 2012 por la Sección Tercera del Consejo de Estado que la autonomía de la actio in rem verso es más de carácter sustancial que procedimental, queda sin discusión reconocer en el enriquecimiento sin causa un verdadero título de imputación. (Bohórquez, 2014, p.294)

En síntesis, para los autores citados, el precedente unificado de la Sección Tercera del alto tribunal de la jurisdicción contenciosa señala que bajo el régimen de responsabilidad estatal contemplado en el artículo 90 de la Carta Magna, el enriquecimiento incausado de las entidades estatales es un título jurídico de imputación de responsabilidad.

Sin embargo, si se toma al enriquecimiento injustificado como un título de imputación, automáticamente pierde su estatus de principio general del derecho y fuente autónoma de obligaciones, lo que aparta a esta figura de sus origenes romanos y anula totalmente a la actio de in rem verso en la jurisdicción contenciosa, pues esta se subsume dentro de las acciones contenciosas de reparación directa y controversias contractuales.

\section{LA ACTIO DE REM IN VERSO EN EL DERECHO COMPARADO}

Para efectos del presente análisis, se reseñarán brevemente un par de autores de Ecuador y Chile que se ocupan de estudiar el tema subexamine, en esas jurisdicciones trasnacionales.

En el derecho ecuatoriano, el instituto del enriquecimiento sin razón válida tiene pleno desarrollo en derecho público, a pesar de no estar positivizado en ningún código, dado que para su aplicación se toma el principio de la equidad, y su prosperidad está supeditada a que coincidan los siguientes elementos esenciales: el lucro de la entidad del Estado, un desmedro patrimonial del prestador, y una acción u omisión de la administración que cuente 
como nexo causal; siendo el objeto de dicha figura el desagravio patrimonial del afectado (Silva Banderas, 2017, p.39).

Lo antes expuesto indica con precisión que en el derecho ecuatoriano se concibe esa figura, la cual para que pueda tener éxito jurídico, similar al caso colombiano, requiere identificar y ratificar que hay disminución patrimonial del prestador, un aumento injustificado del presupuesto estatal, y un vínculo de causa entre ambos, debiendo existir una actuación positiva o negativa de la administración; su objetivo principal es la restauración del equilibrio económico entre las partes, y que su motivo jurídico no está respaldado en la normatividad de orden positivo.

En el país vecino, la acción de reembolso se nutre del principio de equidad, que gobierna todo tipo de actuación o procedimiento judicial incluido el administrativo ejecutado por el Estado.

En suma, la línea jurisprudencial desarrollada en Ecuador se inclina por el reconocimiento de la actio in rem verso como la vía judicial idónea para permitir la resolución de las controversias surgidas ente los particulares y el Estado, pero apartándose de la rigidez que regula todo lo relacionado con la normatividad existente en la contratación estatal, preocupándose especialmente por reparar la desigualdad patrimonial que se forma, el cual, es el adecuado sustento de las circunstancias que originan este medio protector $y$ cómo han de resolverse los desacuerdos en la materia.

Ahora bien, la doctrina foránea en Chile, en el aspecto académico se ha abordado el tema de la siguiente manera: para Díaz García-Huidobro, el enriquecimiento injustificado deviene de un pago de lo no debido, cuando un sujeto incrementa su capital, sin mediar causa justa, a cargo del patrimonio de otro individuo, lo cual es considerado contrario a la equidad y fundamenta la procedencia de una acción para obtener el reembolso de lo perdido (Díaz García-Huidobro, 2012, p.80).

Este trabajo de corte académico inicia analizando el hecho jurídico del pago de lo no debido, y se refiere al articulado 2285 y 2295 del Código Civil chileno, que identifica como regla universal del derecho al enriquecimiento sin causa, el cual ocurre cuando un sujeto logra incrementar, sin justificación legal alguna que lo permita, o sin ningún título, su patrimonio, pero en detrimento o empobrecimiento o disminución patrimonial de otra persona, hecho repro- 
chable socialmente y que atenta contra la equidad, lo que ha impulsado al legislador a regular este tema y ha conferido la posibilidad al perjudicado de ejecutar la acción de reembolso para remediar mediante su imperatividad de cumplimiento, que el injustamente beneficiado deba reembolsar lo inequitativamente apropiado.

El mismo documento reseña que de acuerdo a las autoridades judiciales chilenas, más exactamente la Corte de Apelaciones, se reconoce la importancia de la acción de in rem verso, como la procedente para subsanar el desplazamiento patrimonial sin causa justa, citando para el caso la providencia de fecha septiembre 14 de 1983 (Díaz García-Huidobro, 2012, pp.80-81).

Para este país sudamericano, el concepto de la causa es muy importante en las relaciones jurídicas y comerciales, toda vez que representa uno de los fundamentos del negocio jurídico; sin la causa sería un acto meramente abstracto (Restrepo, 2010, p.215).

Es decir que según lo expuesto por la alta Corte de Chile, mediante el ejercicio de la acción estudiada, se logra frenar el enriquecimiento de quien haya logrado un incremento patrimonial frente a otro, cuando no ha mediado una causa que lo justifique, lo cual es recriminado jurídicamente por obstaculizar el principio de equidad que debe regir en las relaciones de los individuos, sean personas particulares o públicas.

\section{CONCLUSIONES}

La génesis del enriquecimiento sin casusa se remonta al derecho romano, siendo el Digesto 50.17.206, libro noveno Ex varis lectionibus de Pomponio, la referencia más antigua en la que se hace alusión a este principio, según el cual por derecho de la naturaleza es justo que nadie se haga más rico con menoscabo y daño de otra persona.

En Colombia, teniendo en cuenta nuestro sistema jurídico con ascendencia continental europea, el Código Civil consagra varias condictiones romanas, pero la actio de in rem verso, no fue estipulada de manera taxativa en nuestra legislación, siendo aplicada por el máximo órgano de la jurisdicción ordinaria, con base en el artículo 8 de la Ley 153 de 1986, al considerarse el enriquecimiento sin causa como un principio general del derecho. 
El Consejo de Estado ha desarrollado toda una línea jurisprudencial sobre el tema, siendo la sentencia fechada en noviembre 19 de 2012, la aplicable en la actualidad por ser precedente judicial de aplicación obligatoria para las autoridades judiciales y administrativas; en esta sentencia el enriquecimiento sin causa es manejado como un título de imputación de responsabilidad del Estado, tomándose como una pretensión dentro del medio de control de reparación directa, siendo desvalorada su importancia como principio general del derecho y fuente autónoma de obligaciones.

La jurisprudencia dominante descarta la autonomía de la acción bajo estudio, como la vía procesal tradicional para alegar el enriquecimiento injustificado y obtener la debida compensación, y la subsume dentro del medio de control de reparación directa, enmarcándola como un tipo de responsabilidad extracontractual del Estado.

Ante la carencia de la acción de reembolso, son muchos los eventos en que la administración se enriquece en detrimento de un particular sin que este pueda reclamar, con lo cual los principios de buena fe y equidad quedan totalmente subvalorados.

Desde la óptica del derecho sustancial, el enriquecimiento sin causa no puede tramitarse a través de la acción contenciosa de reparación directa, toda vez que esta última es la vía procesal para reclamar por los daños antijurídicos causados por los representantes y agentes del Estado, en el ejercicio de las actividades extracontractuales de la administración, y en el enriquecimiento injustificado no existe un daño antijurídico que reparar, sino un desplazamiento patrimonial que carece de causa.

Podría pensarse que con la vigencia de la Ley 1437 de 2011, y la novedosa figura de la acumulación de pretensiones, se viabilizaría encausar al enriquecimiento sin causa como una pretensión dentro del medio de control de reparación directa, acumulándose una pretensión indemnizatoria con una subsidiaria de carácter compensatorio, sin embargo, este artilugio procesal -si bien puede funcionar para acumular pretensiones conexas, con identidad de procedimiento y juez competente, respetándose los términos de caducidad de cada pretensión-, anula completamente la autonomía de la actio de in rem verso y su carácter excepcional.

Bajo este contexto, es el momento adecuado para que en Derecho Contencioso Administrativo se positivice el enriquecimiento injustificado, como ya se hizo 
en la legislación comercial, y se enmarque a la actio de in rem verso como un procedimiento autónomo, subsidiario, excepcional y de índole compensatorio, con un término de caducidad propio.

Para finalizar y haciendo referencia al derecho comparado, en Ecuador y Chile la figura de la acción de reembolso se contempla como un medio para frenar el pago de lo no debido y el enriquecimiento sin causa, el cual como principio general del derecho no es moral, ni social ni jurídicamente aceptado.

\section{REFERENCIAS}

Arias Fonseca, J. L. (26 de abril de 2013). El enriquecimiento sin causa y la acción in rem versó en materia de responsabilidad estatal por realización de obras, prestación de servicios y suministro de bienes sin contrato estatal. Revista C. U. Americana, (9), 143-181. Recuperado de http://revistascientificas.cuc.edu.co/index.php/juridicascuc/article/viewFile/444/pdf_30

Armenta Ariza, A. M. (10 de diciembre de 2009). El régimen de la responsabilidad patrimonial del Estado en Colombia. Revista Vis luris, (6), 96-97. Recuperado de https:// dialnet.unirioja.es/servlet/articulo?codigo $=3293455$

Baena Gómez, F. J. (2014). Análisis de la Teoría del Enriquecimiento llícito Sin Causa (Tesis de posgrado). Medellín, Colombia: Universidad Santo Tomás. Recuperado de http://repository.usta.edu.co/bitstream/handle/11634/1455/Analisis\%20de\%20 la\%20Teoria\%20del\%20Enriquecimiento\%20llicito\%20sin\%20Causa.pdf?sequence=1\&isAllowed $=y$

Barrientos Grandón, J. (2000). La actio de in rem verso en la literatura francesa de Pothier a L'arret Boudier. Revista de Historia del Derecho Privado (III), 113.

Bohórquez, C. A. (2014). El enriquecimiento sin causa en el derecho civil y administrativo. Bogotá: Universidad Sergio Arboleda.

Cabra Camargo, P. D. (2014). La autonomía de la actio de in rem verso vs la pretensión contenciosa administrativa de reparación directa para alegar el enriquecimiento sin causa (Tesis de maestría). Bogotá, Colombia: Universidad Nacional de Colombia. Recuperado de http://www.bdigital.unal.edu.co/40953/1/46670192.2014.pdf

Consejo de Estado, Sala de lo Contencioso Administrativo (30 de noviembre de 2000). Sección Tercera Sentencia, Radicación número: 11895.

Consejo de Estado, Sala de lo Contencioso Administrativo Sección Tercera (10 de marzo de 2017). Sentencia, 05001-23-31-000-2012-00690-01 (54121)

Consejo de Estado, Sala de lo Contencioso Administrativo, Sección Tercera (30 de marzo de 2006). Sentencia, 25000-23-26-000-1999-01968-01(25662)

Consejo de Estado, Sala de lo Contencioso Administrativo, Sección Tercera (19 de noviembre de 2012). Sentencia, 73001-23-31-000-2000-03075-01(24897)

Consejo de Estado, Sala de lo Contencioso Administrativo, Sección Tercera (30 de enero de 2013). Sentencia, 19.045

Consejo de Estado, Sección Tercera (19 de noviembre de 2012). Salvamento de Voto, 73001-23-31-000-2000-03075-01.

Corte Suprema de Justicia (29 de noviembre de 1936). Sentencia, G.J. 1918 Sala de Casación Civil.

De Coulanges, F. (2003). La Ciudad Antigua. México: Porrúa.

Díaz García-Huidobro, M. (2012). Naturaleza jurídica de la acción por provecho obtenido del dolo ajeno que conceden los artículos 1458 y 2316 del Código Civil (Tesis de 
pregrado). Santiago, Chile: Universidad de Chile. Recuperado de http://repositorio. uchile.cl/handle/2250/112814

García de Enterría, E. (2006). Los principios de la nueva ley de expropiación forzosa. Madrid: Tompson Civitas.

Herrera Montañez, D. A. (2016). El daño y el nexo causal en la pérdida de oportunidad (Tesis de maestría). Bogotá, Colombia: Universidad del Rosario. Recuperado de http://repository.urosario.edu.co/bitstream/handle/10336/12539/ EL\%20DAN\%CC\%830\%20y\%20El\%20NEXO\%20CAUSAL\%20EN\%20LA\%20 PE\%CC\%81RDIA\%20DE\%20OPORTUNIDA.pdf?sequence=1\&isAllowed=y

Meléndez Julio, I. (2015). La responsabilidad contractual y el derecho civil patrimonial en la gestión de los contratos estatales (Tesis doctoral). Colombia: Universidad Nacional de Educación a Distancia. Recuperado de http://e-spacio.uned.es/fez/ eserv/tesisuned:Derecho-Imelendez/MELENDEZ_JULIO_Inocencio_Tesis.pdf

Micolta Gil, G. M. (2014). Marco jurídico de procedencia de la reparación directa en el proceso de contratación estatal (tesis de pregrado). Cali, Colombia: Universidad de Buenaventura. Recuperado de http://bibliotecadigital.usb.edu.co/ bitstream/10819/2496/1/Marco_Juridico_Reparacion_Directa_Contratacion_ Estatal_Micolta_2014.pdf

Navia Arroyo, F. (julio, 2000). La responsabilidad extracontractual del Estado a la luz del artículo 90 de la Constitución Política. Revista de Derecho Privado, (6), 230.

Patiño, H. (2010). Decisiones jurisprudenciales de interés emitidas por la Corte Suprema de Justicia y el Consejo de Estado colombiano relacionadas con la responsabilidad civil extracontractual. Revista de Derecho Privado, (18), 402. Universidad Externado de Colombia. Recuperado de http://revistas.uexternado.edu.co/index.php/derpri/ article/viewFile/408/388

Restrepo, J. M. R. (2010). De los aspectos generales en torno a la doctrina de la causa. Revista Ars Boni Et Aequi, 6(2), 155-218. Recuperado de http://search.proquest.com/ docview/755653901?accountid $=48417$

Ronderos Calderón, Y. A. (2012). Selección del título jurídico de imputabilidad de responsabilidad contra el Estado cuando se presenta el hecho cumplido (Tesis de maestría). Bogotá Colombia: Universidad Nueva Granada. Recuperado de http:// repository.unimilitar.edu.co/bitstream/10654/7841/1/RonderosCalderonYolandaAlicia2012.pdf

Silva Banderas, F. M. (2017). De la teoría del cuasicontrato administrativo a la realidad jurídica del convenio de pago (Tesis de maestría). Quito, Ecuador: Universidad Andina Simón Bolívar. Recuperado de http://repositorio.uasb.edu.ec/ bitstream/10644/5734/1/T2373-MDA-Silva-De\%20la\%20teor\%C3\%ADa.pdf

Useche Perdomo, J. A. (2014). El enriquecimiento sin causa y su aplicación en materia contencioso administrativa en Colombia (Tesis de maestría). Bogotá: Universidad Santo Tomás. Recuperado de http://repository.usta.edu.co/bitstream/ handle/11634/2528/Usechejaimeanx1.pdf?sequence=2\&isAllowed=y

Valencia Zea, A. y Ortiz Monsalve, A. (1998). Derecho Civil. De las Obligaciones. Bogotá: Temis.

Valencia Zea, A. y Ortiz Monsalve, A. (2011). Derecho Civil. Parte General y Personas. Bogotá: Temis.

\section{Legislación y otros documentos}

Colombia, Constitución Política de Colombia (1991). Bogotá.

Colombia, Ley 1437 (2011). Bogotá.

Colombia, Ley 84 (1873). Bogotá. 